\title{
Synthesis and Characterization of Imide Containing Hybrid Epoxy Resin with Improved Mechanical and Thermal Properties
}

\author{
U. G. Rane, A. A. Sabnis, and V. V. Shertukde \\ Department of Polymer and Surface Engineering, Institute of Chemical Technology, Matunga, Mumbai, India \\ Correspondence should be addressed to V. V. Shertukde; vikrantshertukde16@gmail.com
}

Received 6 January 2014; Revised 16 April 2014; Accepted 26 May 2014; Published 24 July 2014

Academic Editor: Jose Ramon Leiza

Copyright ( 2014 U. G. Rane et al. This is an open access article distributed under the Creative Commons Attribution License, which permits unrestricted use, distribution, and reproduction in any medium, provided the original work is properly cited.

\begin{abstract}
Phosphorous containing amine, tripropyldiamine phosphine oxide (TPDAP), and hybrid monomer 4-(N-phthalimidophenyl) glycidylether (PPGE) were synthesized and characterized by Fourier transform infrared (FTIR) spectroscopy, nuclear magnetic resonance (NMR) spectroscopy, and elemental analysis (EDX). PPGE was incorporated in bisphenol A epoxy resin (BPA) in various concentrations ( $5 \%$ to $20 \%$ ), based on a weight percentage of BPA resin. Curing was carried out with the stoichiometric amount of TPDAP and 1,3-propanediamine (PDA) to result in cross-link network. Various mechanical, chemical, thermal, and flame retardant properties of modified and unmodified epoxy resin were studied. The coatings obtained with the addition of PPGE were found to have improved properties as compared with those of the unmodified resin. Coatings with $15 \%$ loading of PPGE showed improved flame retardant and mechanical properties with stable thermal behaviour.
\end{abstract}

\section{Introduction}

Epoxy resins have been extensively used in many industrial applications such as coatings, adhesives, composites, laminates, and encapsulants for electronic packaging because of their low cost, good chemical and electrical resistance, low shrinkage upon curing, and outstanding mechanical properties. However, the flammability of epoxy resin is a serious limitation in areas requiring high flame retardancy. Many approaches have been reported for improving the flame retardancy of epoxy resins $[1,2]$. Halogen-containing compounds have been reported to be effective flame retardant agents for various epoxy resins. However, they are not always acceptable because of the release of highly toxic and corrosive fumes during combustion [3, 4]. Environmental concerns and legislation are driving the search of new, halogen-free flame retardant reagents used in epoxy resins. Phosphorus, nitrogen, and silicon compounds are the agents mostly used for replacing halogen-containing compounds in the flame retardant epoxy resins. The combination of different types of these flame retardants can lead to the synergistic improvement in the flame retardancy of epoxy resins [5]. The modification of epoxy resins with polyimides or imidocompounds can be a convenient approach of enhancing the glass transition temperature and thermal stability of epoxy resin by providing char formation in the condensed phase. Hence imide modified epoxy resins by either physical blending or chemical reactions have been reported to show good flame retardant properties. The main common advantages of nitrogen compounds are their low toxicity and in case of fire the absence of dioxin and halogen acid as well as their low evolution of smoke [6-8].

Organophosphorus compounds have demonstrated a good ability as flame retardants for polymeric materials. They can form carbonaceous char during combustion, which acts as a physical barrier to insulate heat from the flame and to prevent the diffusion of combustible gases [9-11].

In this paper, the nitrogen-phosphorous synergistic effect on flame retardancy was studied by incorporating rigid imide and phosphorous group in diglycidylether of bisphenol A (BPA) resin. In the present study hybrid monomer (PPGE) containing oxirane ring as well as imide group and a phosphorous containing amine (TPDAP) were synthesized. The syntheses were carried out according to reported procedures $[12,13]$. The synthesized monomer and amine were characterized for their chemical structure by FT-IR, $\mathrm{H}^{1} \mathrm{NMR}$, and elemental analysis. The effect of addition of imide and 


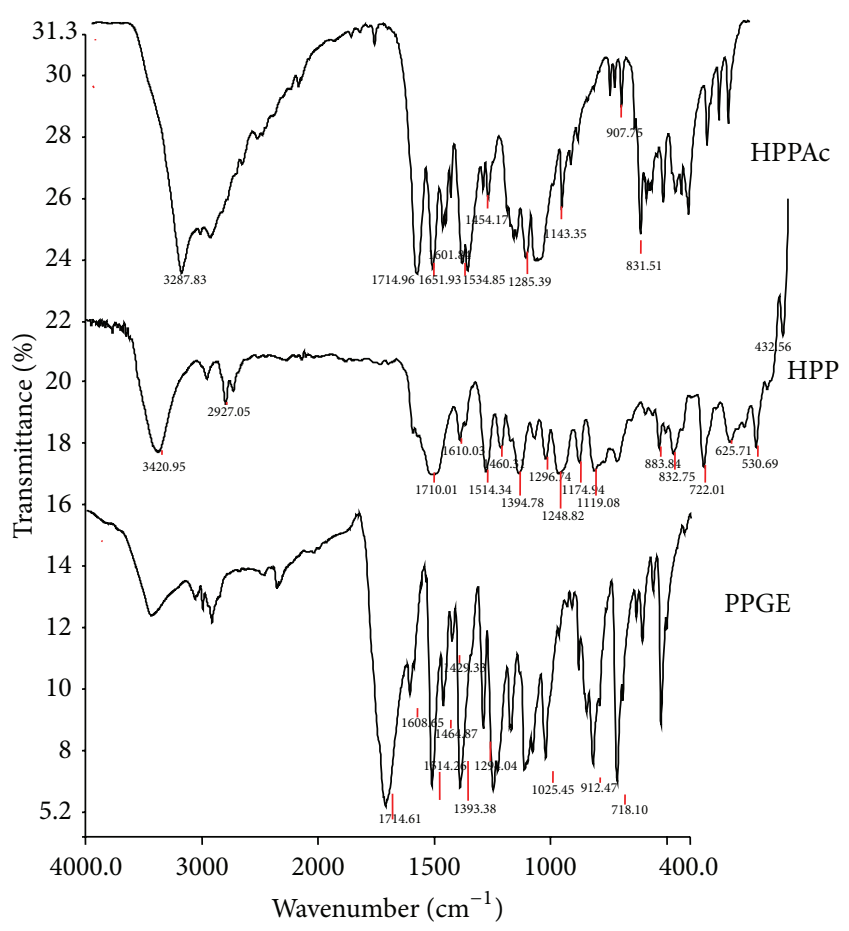

FIgURE 1: FT-IR spectra of HPPAc, HPP, and PPGE.

phosphorous groups on various physicomechanical, chemical, thermal, and flame retardant properties of modified and unmodified resin was investigated.

\section{Experimental}

2.1. Materials. Phthalic anhydride, p-aminophenol, ptoluenesulfonic acid, epichlorohydrin, benzyltriethylammonium chloride, phosphorous oxychloride, and 1,3-propane diamine were purchased from S. D. Fine chemicals. Glycidylether of bisphenol A DGEBA (epoxy equivalent,190) was obtained from Pliogrip, Mumbai.

2.2. Synthesis of $\mathrm{N}$-(4-Hydroxyphenyl) Phthalamic Acid $(H P P A c)$. In a 3-necked flask equipped with a mechanical stirrer and a reflux condenser, phthalic anhydride $(86.4 \mathrm{~g})$ dissolved in $700 \mathrm{~mL}$ of acetone was charged. The solution was stirred at ambient temperature and 4-aminophenol (87.2 g) was added in portions over $30 \mathrm{~min}$. The reaction mixture turned into white slurry. After stirring for 3.5-4 hrs, the slurry was filtered. The solid was washed with acetone and dried at $50^{\circ} \mathrm{C}$ under vacuum to give a white powder product (yield: $88 \%)$.

IR $\left(\mathrm{KBr}, \mathrm{cm}^{-1}\right)$ (Figure 1): 2900-3200 (-COOH), 3287 (N-H), 1601, 1534 (-Ar) $1714(\mathrm{C}=\mathrm{O})$.

2.3. Synthesis of $\mathrm{N}$-(4-Hydroxyphenyl) Phthalimide (HPP). In a 3-necked flask equipped with a mechanical stirrer, a water segregator, and a reflux condenser, HPPAc (123.2 g), p-toluenesulfonic acid $(8.75 \mathrm{~g})$, dimethylformamide $(60 \mathrm{~mL})$, and toluene $(100 \mathrm{~mL})$ were charged. The mixture was heated to reflux for about 9 hrs until the slurry turned into a clear solution and the stoichiometric amount of water was segregated. After removing toluene, the residue was poured into a large amount of water. The precipitate was collected by filtration and washed with $5 \mathrm{wt} \%$ sodium bicarbonate solution and with water. The crude product was recrystallized from mixed solvent of water-isopropanol $(1: 1 \mathrm{v} / \mathrm{v})$ to give a gray product (yield: 70\%).

$$
\begin{aligned}
& \text { IR }\left(\mathrm{KBr}, \mathrm{cm}^{-1}\right) \text { (Figure 1): } 3420(-\mathrm{OH}), 1248(\mathrm{C}-\mathrm{N}) \text {, } \\
& \text { 1710, } 1610(\mathrm{C}=\mathrm{O}), 2927(\mathrm{C}-\mathrm{H}), 1514,1394 \text { (aromatic } \\
& \text { ring). }
\end{aligned}
$$

2.4. Synthesis of 4-(N-Phthalimidophenyl) Glycidylether (PPGE). HPP (18.7 g) was mixed with $100 \mathrm{~g}$ of epichlorohydrin $(\mathrm{ECH})$ in a 3-necked flask equipped with a stirrer, condenser, and a nitrogen inlet; to the above reaction mixture benzyltriethylammonium chloride $(1.8 \mathrm{~g})$ was added and the mixture was stirred under a nitrogen atmosphere for $24 \mathrm{~h}$ at $80^{\circ} \mathrm{C}$. Excess of ECH was removed under reduced pressure and solid residue was dissolved in ethyl acetate, washed with water, and dried over MgSO4 to give PPGE (yield 60\%).

Epoxy equivalent weight (192).

2.5. Synthesis of Tripropyldiamine Phosphine Oxide. In a 3necked flask equipped with a stirrer, condenser, and nitrogen inlet the solution of $10 \mathrm{~mL}$ toluene and $2.67 \mathrm{~mL}(0.03 \mathrm{moL}+$ $0.01 \mathrm{moL}$ excess) of 1,3-propanediamine was taken and the solution of $0.93 \mathrm{~mL}$ of $\mathrm{POCl}_{3}$ in $20 \mathrm{~mL}$ toluene was added dropwise with continuous stirring in $30 \mathrm{~min}$, at a rate that the temperature of the reaction mixture cooled to $0^{\circ} \mathrm{C}$ is not allowed to exceed $5^{\circ} \mathrm{C}$. After stirring for $2 \mathrm{~h}$ at $60^{\circ} \mathrm{C}$ the toluene was removed by decantation and a solution of $2.04 \mathrm{~g}$ $\mathrm{NaOEt}$ and $60 \mathrm{~mL}$ of $96 \% \mathrm{EtOH}$ was added and the mixture was stirred for $3 \mathrm{~h}$ at $60^{\circ} \mathrm{C}$. The formed $\mathrm{NaCl}$ was filtered to give the liquid product ( $80 \%$ yield).

Amine value: $406 \mathrm{mg}$ of $\mathrm{KOH} / \mathrm{gm}$.

\section{Characterization}

\subsection{Characterization of the PPGE and TPDAP}

3.1.1. Fourier Transform Infrared (FTIR) Spectroscopy. The FTIR spectrum of the polymer in $\mathrm{KBr}$ pallets was recorded using a Perkin-Elmer Spectrum GXA FTIR spectrometer at a resolution of $4 \mathrm{~cm}^{-1}$ taking 16 scans. The range of spectrophotometer is $400-4,000 \mathrm{~cm}^{-1}$.

3.1.2. Nuclear Magnetic Resonance (NMR) Spectroscopy. The NMR measurements were recorded with a Bruker MSL$300(300 \mathrm{MHz})$ NMR spectrometer with DMSO-d6 as a solvent, at $25^{\circ} \mathrm{C}$, with tetramethylsilane (TMS) as the internal reference.

3.1.3. Elemental Analysis (EDX). Elemental analysis of synthesized monomer and amine was performed with a Zeiss Supra 40 rapid element analyzer employing acetanilides as a standard. 
3.2. Method for the Evaluation of the Mechanical Properties of the PPGE Modified Epoxy Coatings. Different mechanical and chemical resistance properties of coated panels and films were evaluated as per the following standard test methods.

3.2.1. Scratch Hardness. Scratch hardness was carried out as per ASTM D-2197. The scratch resistance of the cured samples was determined using an automatic scratch hardness tester having a hard end steel hemispherical point of $1 \mathrm{~mm}$ diameter as a scratching needle. The test was moved at a fixed speed of $3 \mathrm{~cm} /$ beneath the point of scratching needle. The scratch resistance is reported as the weight on the stylus to tear off the coating. This test simulates scratching by sharp objects.

3.2.2. Pencil Hardness. Pencil hardness of coating was determined as per ASTM D 3363 using pencil hardness tester with calibrated set of drawing leads ranging from $6 \mathrm{~B}$ (the softest) to $6 \mathrm{H}$ (the hardest). The process was started with softest pencil to end with hardest pencil. A scratch hardness value of the films is equal to the hardness value of the pencil that tears the film.

3.2.3. Impact Resistance. Tubular impact resistance test was conducted as per ASTM D2794 to predict the ability of the coating to resist cracking caused by rapid deformation. It is reported in terms of inch-pound (height-load). Tubular impact resistance test was carried out using an indenter with hemispherical head of diameter $0.625 \mathrm{inch}$ and $2 \mathrm{lb}$ load.

3.2.4. Flexibility. The conical mandrel bend test of the coatings was carried out as per ASTM D522. The mandrel bend test is a measure of flexibility of coating. As applied coat was dried enough, the prepared panels were kept between the mandrel and draw bar. The lever bar was drawn down at uniform velocity to bend the specimen approximately 1358 . The bent surface was observed for crack or other surface defects.

3.2.5. Gloss. Gloss is a measure of ability of coated surface to reflect light at a particular angle without scattering. Gloss was determined according to ASTM D523-67. Gloss of the cured sample was measured at angles 458 and 608 using a digital minigloss meter calibrated against internal standard, that is, refractive index (Komal Scientific Co., Mumbai, India), and the results are reported in terms of gloss unit (GU).

3.2.6. Cross-Hatch Adhesion. This test was carried out as per ASTM D3359-83. Crosscut adhesion tape test is used to assess the adhesion of coating films to metallic substrates. Cuts were made on the coating in one steady motion with sufficient pressure on the cutting tool having a cutting edge angle between 158 and 308. After making two such cuts at 908 the grid area was brushed and a $2.5 \mathrm{~cm}$ wide semitransparent pressure sensitive adhesive tape was placed over the grid. After $30 \mathrm{~s}$ of application, the tape was removed rapidly and the grid was inspected according to the standards. The amount of coated area retained under the tape corresponds to the adhesion efficiency of the coating. The more the coated material removed by the tape, the poorer the adhesion of the coating to the substrate.

3.2.7. Tensile Strength. Tensile strength as per ASTM D 638 was evaluated using universal tensile testing machine LR50k from Lloyd instruments Ltd, UK, at a crosshead speed of $50 \mathrm{~mm} / \mathrm{min}$. The specimen for tensile test was dumbbell cut from the films that were prepared on glass substrates and had a thickness of about $30-40 \mathrm{~mm}$. A benchmark and the original cross-sectional area were utilised to calculate their tensile properties. The ultimate tensile strength and elongation were automatically calculated by the computer connected to machine. The average of at least five measurements for each sample was reported, and the experimental error is ${ }^{\wedge} 10$ per cent.

\subsection{Method for the Evaluation of Thermal and Flame Retar- dant Properties of PPGE Modified Epoxy Coatings}

3.3.1. Differential Scanning Calorimetry (DSC). Glass transition temperature of the blends was determined using TA instruments model 2920 differential scanning calorimeter. In order to determine the $\mathrm{Tg}$ of the blends, they were heated from 40 to $150^{\circ} \mathrm{C}$ at a heating rate of $10^{\circ} \mathrm{C} / \mathrm{min}$ in nitrogen atmosphere.

3.3.2. Thermogravimetric Analysis (TGA). Thermogravimetric data were obtained from $2-10 \mathrm{mg}$ samples under a nitrogen atmosphere at a heating rate of $10^{\circ} \mathrm{C} / \mathrm{min}$ from room temperature to $800^{\circ} \mathrm{C}$ using TGA 2050 thermogravimetric analyzer.

3.3.3. Limiting Oxygen Index (LOI). The LOI is the minimum fraction of oxygen in a mixture of oxygen and nitrogen which could just support flaming combustion. The LOI tests were performed according to the testing procedure of ASTM D 2863-77 with test specimen films of $14 \mathrm{~cm}$ in length and $52 \mathrm{~mm}$ in width. The sample was suspended vertically and ignited by a Bunsen burner. The flame was removed and the timer was started. The concentration of oxygen was raised if the specimen was extinguished before passing 100 reference marks or within $3 \mathrm{~min}$. The oxygen content was adjusted until the limiting concentration was determined. LOI was determined using Dynisco polymer test instrument model number 18-3266-00.

\subsection{Method for the Evaluation of the Chemical Properties of the PPGE Modified Epoxy Coatings}

3.4.1. Chemical Resistance. Resistance to acid and alkali was determined by using ASTM D-4274-88 standard while for detergent resistance standard ASTM D-2248a was followed.

For this test, the coated panels were immersed in 5 per cent solution of HCL (acid), 5 per cent solution of $\mathrm{NaOH}$ (alkali), and 5 per cent solution of detergent. The immersed panels were maintained at constant temperature. The panels were removed for examination after $6,12,18$, and 24 hours 
<smiles>O=C1OC(=O)c2ccccc21</smiles>

Phthalic anhydride<smiles>Nc1ccc(O)cc1</smiles>

p-Aminophenol<smiles>CC(C)(C)[14C](C)([14CH3])[14CH3]</smiles>

$\mathrm{N}$-(4-Hydroxyphenyl)phthalamic acid

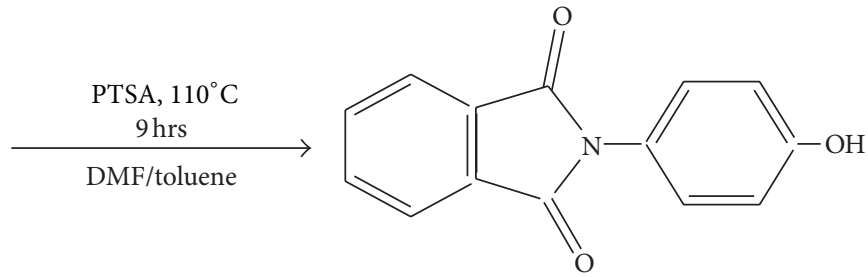

N-(4-Hydroxyphenyl)phthaliimide

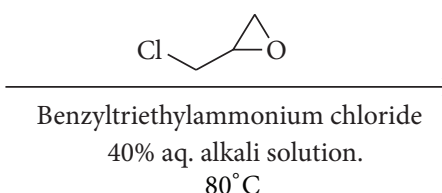

$80^{\circ} \mathrm{C}$

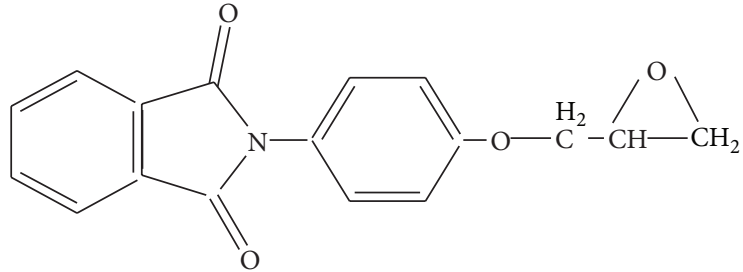

N-(4-Phthaliimidophenyl)glycidylether

Scheme 1: Synthesis of PPGE.

from the start of the test and observed for loss of adhesion, blistering, popping, or any other deterioration of the film.

3.4.2. Solvent Resistance. The resistance of the coating towards the solvents like methyl ethyl ketone (MEK) and xylene was determined as per the procedure given in ASTM D-5402-93. The coated panels were rubbed with the cotton moist with respective solvent and observed for any softness of the film, peeling of the film, and loss of gloss.

3.5. Method for Coating Formulation and Its Application. PPGE was mixed with bisphenol A resin (BPA) in different mole ratios from $5 \%$ to $20 \%$ and blends were prepared. TPDAP and 1,3-propanediamine were used as curing agent for resin system, and solvent system used for film application was toluene and butanol $(70: 30)$. PPGE was dissolved in solvent and heated slightly to get a homogenous solution; it was filtered to remove any impurities, the homogenous solution was cooled, and stiocheometric amount of DGEBA and curing agent were added with stirring.

Films were cast on glass plate, on teflon, and on M.S panels. The cure cycle followed for films and coated panels was $100^{\circ} \mathrm{C} / 2$ hours and $120^{\circ} \mathrm{C} / 2$ hours. The films had thickness of 35-40 $\pm 1 \mu \mathrm{m}$. Prior to testing the samples were allowed to stabilize at $50 \%$ humidity and at $30^{\circ} \mathrm{C}$ for 7 days.
TABLE 1: Sample codes and resin formulations.

\begin{tabular}{lcccc}
\hline Sample code & BPA & PDA & TPDAP & \multirow{2}{*}{ PPGE (\%) } \\
& G & g & g & \\
\hline BPA-PDA & 15 & 1.6 & - & - \\
BPA-TPDAP & 15 & - & 1.3 & - \\
BPA-5PPGE & 15 & - & 1.4 & 5 \\
BPA-10PPGE & 15 & - & 1.6 & 10 \\
BPA-15PPGE & 15 & - & 1.8 & 15 \\
BPA-20PPGE & 15 & - & 2.1 & 20 \\
\hline
\end{tabular}

The panels were subjected to different testing procedures to evaluate their mechanical properties and their durability.

Sample code used for the resin formulation was enlisted in Table 1.

\section{Results and Discussion}

4.1. Characterization of Synthesized PPGE and TADAP. To characterize the chemical structure of PPGE and TPDAP, the sample was subjected to FT-IR, ${ }^{1} \mathrm{H}$ NMR, and EDX analysis. Synthetic route for PPGE and TPDAP were shown in Scheme 1 and Scheme 2, respectively. 


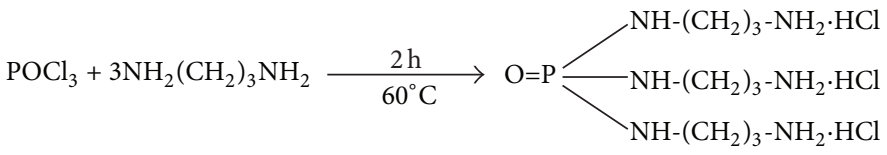

Phosphorous oxychloride

1,3-Propanediamine

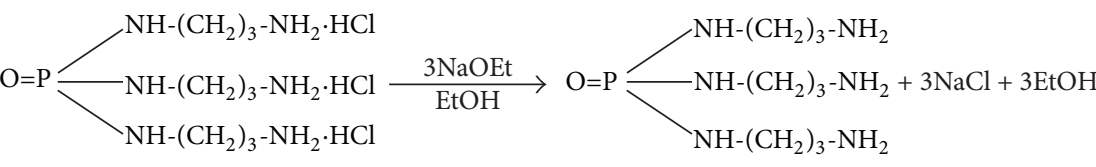

Tipropyldiamine phosphine oxide

Scheme 2: Synthesis of tripropyldiamine phosphine oxide.

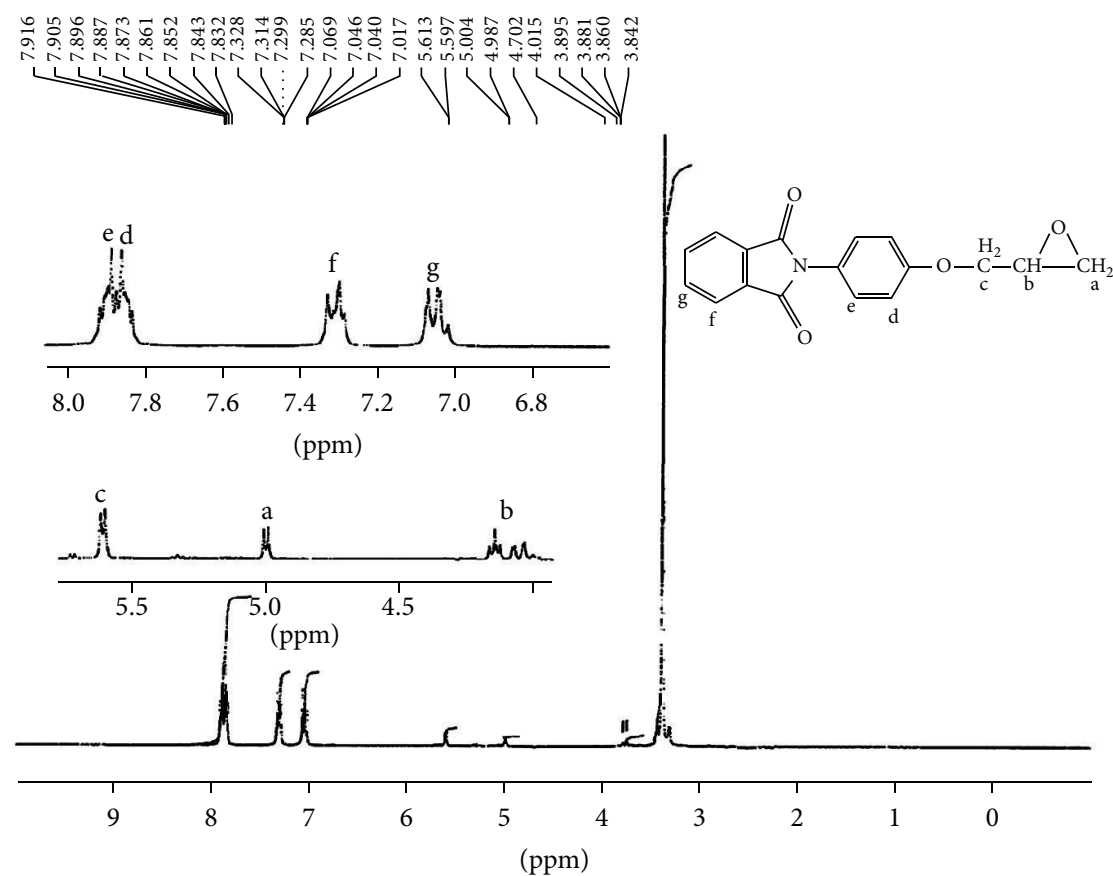

Figure $2:{ }^{1} \mathrm{H}$ NMR for PPGE.

4.1.1. Structural Confirmation of PPGE. Imide containing glycidylether (PPGE) and phosphorous containing amine were successfully synthesized and analyzed. The chemical structure of the compounds was characterized by FTIR, $1 \mathrm{H}$ NMR, and EDX. The absorption peak at around $822 \mathrm{~cm}^{-1}$ was observed in the FTIR spectrum of PPGE (Figure 1) demonstrating the formation of oxirane groups. The peaks obtained at 718 ( $\mathrm{C}=\mathrm{O}$ bending), 1714 ( $\mathrm{C}=\mathrm{O}$ symmetric stretching), $1608,1514,1464,1393$ (C-C stretching of aromatic ring), 1393 (C-N stretching), 1294, 1025 ( $\mathrm{Ph}-\mathrm{O}-\mathrm{CH}_{2}$ ), and 912 (oxirane ring) gave more evidence to the obtained compound having the expected chemical structure.

Further characterization was performed with $\mathrm{H}^{1} \mathrm{NMR}$ (Figure 2). The specific absorption peaks were observed at $\delta=$ 4.9 and 5.0 (doublet, a), $\delta=3.8-4$ (multiplet, b), $\delta=5.6$ and 5.59 (doublet, c), $\delta=7.8-7.9$ (multiplet, $\mathrm{d}$ and e), $\delta=7.2-7.3$ (multiplet, f), and $\delta=7.01-7.06$ (multiplet, g).

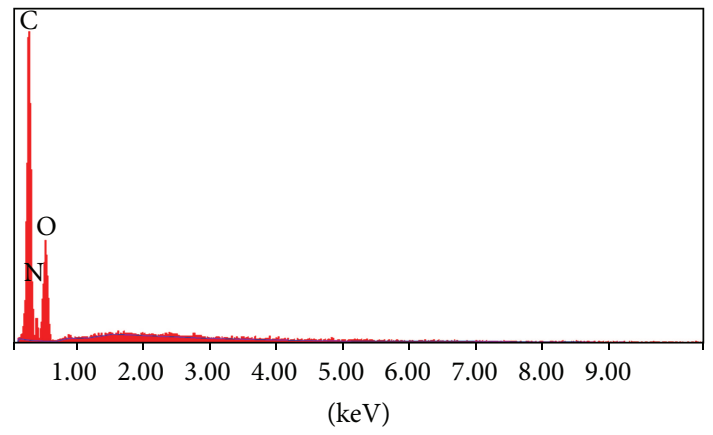

FIGURE 3: Elemental analysis of PPGE.

Elemental analysis (Figure 3): calc. \%: C: 68.53, N: 5.52, O: 21.65 ; found $\%$ : C: $69, \mathrm{~N}: 4.74, \mathrm{O}: 21$; from above chemical analysis structure of PPGE can be confirmed. 


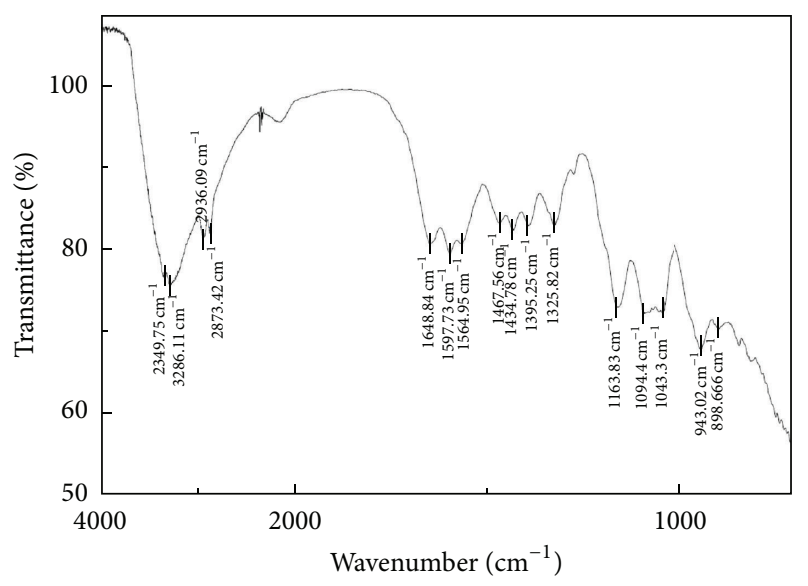

FIGURE 4: FT-IR spectra of TPDAP.

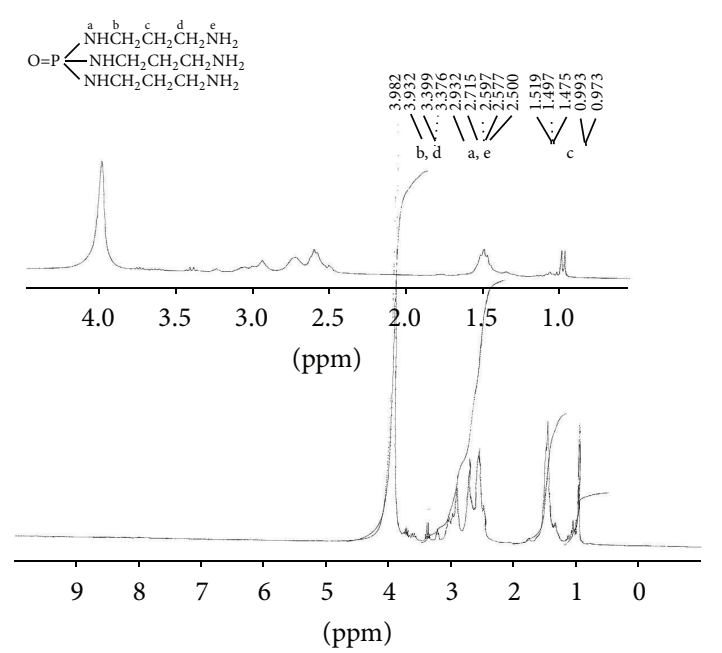

FIgURE $5:{ }^{1} \mathrm{H}$ NMR for TPDAP.

4.1.2. Structural Confirmation for TPDAP. The structure of phosphorous containing amine was confirmed form FTIR and ${ }^{1} \mathrm{H}$ NMR. Characteristic peaks for FTIR (Figure 4) are as follows: doublet at 3349 and $3286\left(\mathrm{NH}_{2}\right), 1648(\mathrm{~N}-\mathrm{H}$ bending), $1325(\mathrm{C}-\mathrm{N}), 2936-2837(\mathrm{C}-\mathrm{H}), 1163(\mathrm{P}=\mathrm{O})$, and 898 $(\mathrm{P}-\mathrm{O})$.

${ }^{1} \mathrm{H}$ NMR (Figure 5): the specific absorption peaks were observed at $\delta=2.5-2.9$ (multiplet, a, e); $\delta=3.3-3.9$ (multiplet, b, d); $\delta=0.97-1.52$ (multiplet, c). Elemental analysis (Figure 6): calc. \%: C: 40.29, H: 10.07, N: 31.34, O: 5.97, P: 11.55; found \%: C: 40, H: 9.78, N: 31, P: 11.22, O: 5.80.

The epoxy equivalent value and amine value of the synthesized PPGE and TPDAP, respectively, were determined by volumetric titration which coincides with the expected values. The synthesized hybrid monomer PPGE and curing agent TPDAP were incorporated to increase the thermal stability and flame retardancy of the epoxy resin. Scheme 3 shows reaction between epoxy resin and amine.

4.2. Mechanical and Chemical Properties of Epoxy ResinPPGE Coatings. The data of mechanical properties (pull-off,

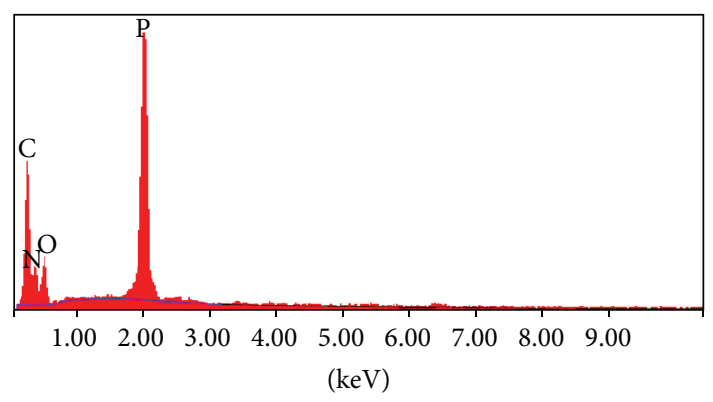

FIgURE 6: Elemental analysis of TPDAP.

impact, bending, gloss breakdown voltage, and hardness) was listed in Table 2. The data reported on adhesion (pulloff) indicates that all cured epoxy resin systems showed good adhesion with steel. Scratch hardness values reveal that system up to $15 \%$ loading of PPGE showed higher scratch hardness. This can be attributed to the aliphatic nature of the amine which is known to confer flexibility to the systems, while rigid aromatic moieties from PPGE impart hardness. It was observed that above 15\% PPGE loading scratch hardness decreases due to increasing amount of aromatic content; an increased number of aromatic moieties after an optimum amount of loading reportedly produce steric hardness within the polymer film network [14], which hinders the free movement of polymeric chain and deteriorates the hardness and flexibility of the coating. Same explanation goes for Tbend and impact resistance which shows the same trend as scratch hardness test. The tensile strength of the film increases considerably and elongation at break obviously decreases with increasing crosslinking.

The higher gloss and breakdown voltage values (B.D.V) were observed for coating with increasing PPGE loading. This can be correlated to the polar hydroxyls, oxirane, and increasing the aromatic content in the backbone of the polymeric chain of the resin, which on curing with polyamine produces more dense and cross-linked structure [15].

The coating samples were tested for their chemical resistance properties. The results of the tests are shown in Table 3. It was observed that all coatings show good solvent, acid, and water resistance, whereas coatings above $15 \%$ loading of PPGE showed weak alkali resistance resulting in loss of adhesion and in partial peeling off the coating.

\subsection{Thermal Properties of Epoxy Resin-PPGE Coatings}

4.3.1. Differential Scanning Calorimetry Study BPA/PPGE Films. The glass-transition temperature ( $\mathrm{Tg}$ ) of cured films was shown (Figure 7). It was observed that the Tg of BPAPPGE and BPA-PDA showed higher values as compared to Tg of BPA-TADAP. The relatively poor Tg of the BPATPDAP cured epoxy resin comes from the phosphorous of the TPDAP, which degrades at relatively low temperatures as well as reducing cross-link density and rigidity of polymer network, resulting in the decrease of Tg. The same phenomenon was observed for other phosphorylated epoxy resins $[16,17]$ and polymers. In case of BPA-PPGE system 
TABLE 2: Mechanical properties of epoxy resin-PPGE coatings.

\begin{tabular}{|c|c|c|c|c|c|c|}
\hline \multirow{2}{*}{ Properties } & \multicolumn{6}{|c|}{ Sample code } \\
\hline & BPA-PDA & BPA-TPDAP & BPA-5PPGE & BPA-10PPGE & BPA-15PPGE & BPA-20PPGE \\
\hline Adhesion (\%) & 100 & 100 & 100 & 100 & 100 & 100 \\
\hline $\begin{array}{l}\text { Impact resistance } \\
(\mathrm{kg} / 0.6 \mathrm{~m})\end{array}$ & 0.40 & 0.40 & 0.50 & 0.55 & 0.50 & 0.50 \\
\hline Pencil hardness & $2 \mathrm{H}$ & $2 \mathrm{H}$ & $2 \mathrm{H}$ & $3 \mathrm{H}$ & $4 \mathrm{H}$ & $4 \mathrm{H}$ \\
\hline T-bend (1/8 in.) & Pass & Pass & Pass & Pass & pass & fail \\
\hline Scratch resistance (gm) & 2000 & 2000 & 2500 & 2800 & 3500 & 3400 \\
\hline $\mathrm{BDV}(\mathrm{KV} / \mathrm{mil})$ & 2.95 & 4.26 & 5.09 & 5.43 & 5.91 & 6.58 \\
\hline Gloss@60 & 50 & 52 & 60 & 65 & 72 & 78 \\
\hline $\begin{array}{l}\text { Tensile strength } \\
\mathrm{MPa}\end{array}$ & 25.12 & 29.45 & 30.62 & 44.80 & 46.69 & 51.77 \\
\hline
\end{tabular}
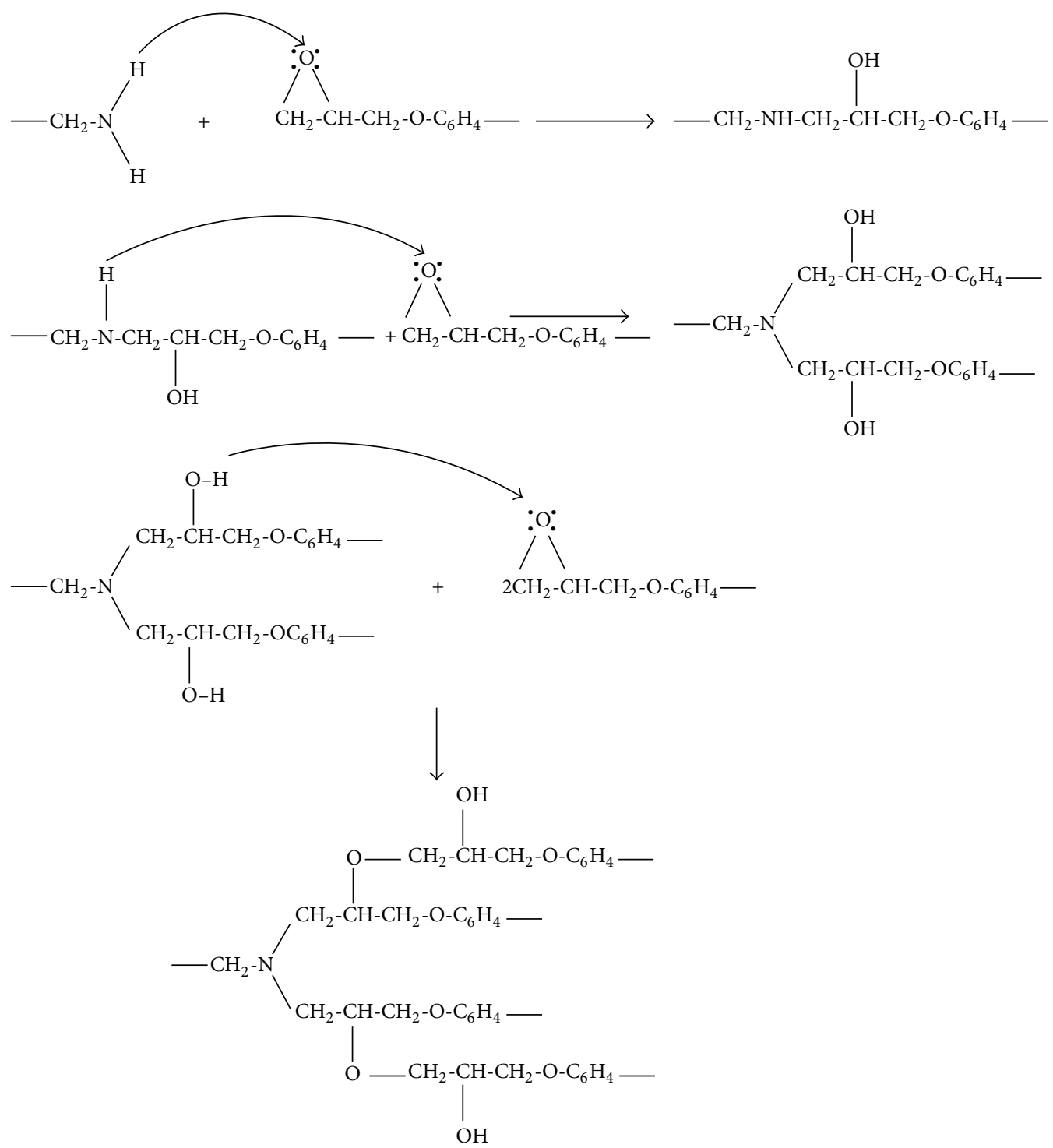

Scheme 3: Reaction between epoxy resin and amine. 
TABLE 3: Chemical properties of epoxy resin-PPGE coatings.

\begin{tabular}{|c|c|c|c|c|c|c|}
\hline \multirow{3}{*}{ Sample code } & \multicolumn{6}{|c|}{ Properties } \\
\hline & \multirow{2}{*}{$10 \% \mathrm{NaCl}$} & \multirow{2}{*}{ Alkali resistance } & \multirow{2}{*}{ Distilled water } & \multirow{2}{*}{ Acid resistance } & \multicolumn{2}{|c|}{ Solvent resistance } \\
\hline & & & & & Xylene & MEK \\
\hline BPA-PDA & 1 & 1 & 1 & 1 & 1 & 1 \\
\hline BPA-TPDAP & 1 & 1 & 1 & 1 & 1 & 1 \\
\hline BPA-5PPGE & 1 & 1 & 1 & 1 & 1 & 1 \\
\hline BPA-10PPGE & 1 & 1 & 1 & 1 & 1 & 1 \\
\hline BPA-15PPGE & 1 & 2 & 1 & 1 & 1 & 1 \\
\hline BPA-20PPGE & 1 & 4 & 1 & 1 & 1 & 1 \\
\hline
\end{tabular}

Note: 1: not affected; 2: loss in gloss; 3: blistering; 4: slight loss of adhesion; 5: film partially removed; 6: film completely removed.

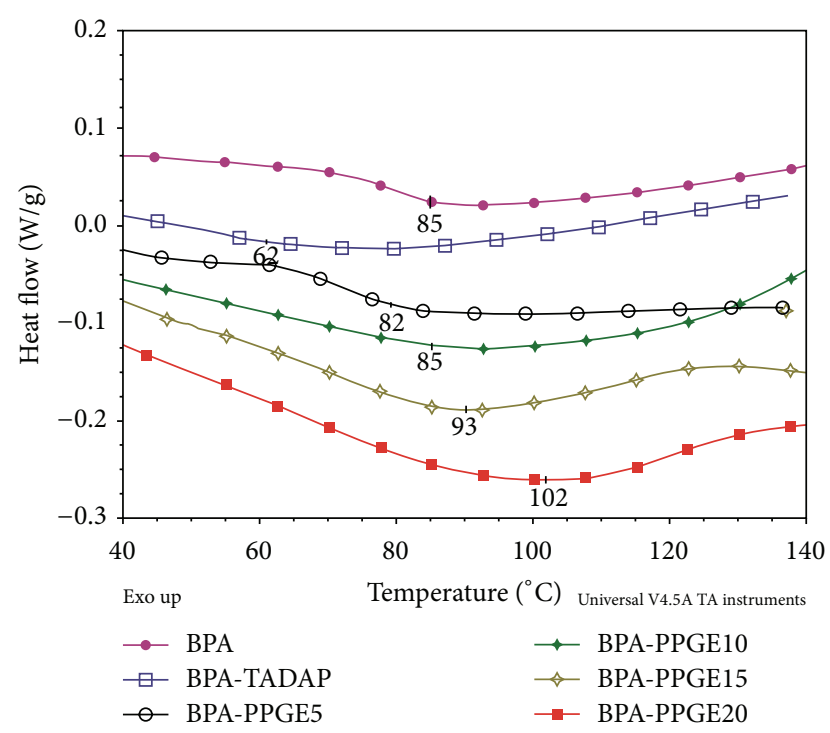

FIGURE 7: The DSC curves of epoxy-PPGE films in nitrogen at $10^{\circ}$ $(\mathrm{C} / \mathrm{min})$ heating rate.

the phthaliimide content of the films increases from 5 to $20 \%$ which compensate for the increasing phosphorous content of the system. leading to the enhancement of Tg of BPA-PPGE system.

Hence BPA-PPGE system showed higher Tg as compared to Tg of PPGE-TPDAP which decreases rapidly as compared to BPA-PDA system.

4.3.2. Flame Retardancy of Epoxy-PPGE Films. Incorporating imide and phosphorous groups into an epoxy resin matrix resulted in the improvement of the flame retardancy of the resin, which can be clearly seen from LOI values (Table 4). The cured epoxy resin system exhibited good char yields. Increasing char formation could limit the formation of combustible gases, decrease the exothermicity of the pyrolysis reactions, and decrease the thermal conductivity of the resins and consequently limit the resin flammability. The polymer forming high char yield leading to high flame retardancy has been demonstrated $[18,19]$. It was reported that phosphorous when incorporated into polymers as an additive or as reactive comonomer is known to impart fire retardation by condensed
TABLE 4: LOI values of epoxy-PPGE films.

\begin{tabular}{lcc}
\hline Sample code & LOI values & LOI values calculated \\
\hline BPA-PDA & 19 & 19.9 \\
BPA-TPDAP & 21 & 21.5 \\
BPA-5PPGE & 25 & 25.1 \\
BPA-10PPGE & 26 & 25.9 \\
BPA-15PPGE & 27 & 27.5 \\
BPA-20PPGE & 29 & 28.3 \\
\hline
\end{tabular}

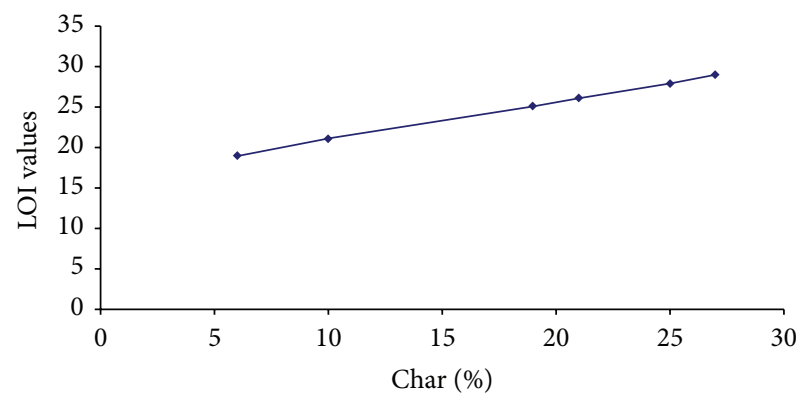

FIGURE 8: The plot of the epoxy resins' char yields versus LOI values. The straight line represents Krevelen's equation: LOI $=17.5+0.5(\sigma)$.

phase and gas phase mechanism [20]. Additionally improved flame retardancy can be attributed to imide groups present in the structure which results in the synergistic effect between phosphorous and nitrogen as the literature reported [21]. The combined effect of imide and phosphorous has resulted in the increase of LOI values.

The LOI values of the epoxy resins increase linearly with increasing the phthalimide groups and phosphorous contents (Figure 8). Moreover, the measured LOI values coincide with the values calculated from Krevelen's equation for

$$
\mathrm{LOI}=17.5+0.4(\sigma)
$$

Here $\sigma$ is the polymer's char ratio (Figure 8). It can be concluded that the developed maleimide-phosphorus containing epoxy resin system is a halogen-free flame retardant system with good thermal properties and applications in the environment friendly "green" products. 
TABLe 5: TGA analysis of epoxy-PPGE system.

\begin{tabular}{|c|c|c|c|c|c|}
\hline Sample code & Onset $\left({ }^{\circ} \mathrm{C}\right)$ & Endset $\left({ }^{\circ} \mathrm{C}\right)$ & $T_{\max }\left({ }^{\circ} \mathrm{C}\right)$ & Char yield at $700^{\circ} \mathrm{C}(\%)$ & $T_{g}\left({ }^{\circ} \mathrm{C}\right)$ \\
\hline BPA-PDA(a) & 200 & 570 & 333 & 6 & 85 \\
\hline BPA-TPDAP(b) & 190 & 544 & 318 & 10 & 65 \\
\hline BPA-5PPGE(c) & 175 & 560 & 285 & 19 & 82 \\
\hline BPA-10PPGE(d) & 170 & 563 & 292 & 21 & 85 \\
\hline BPA-15PPGE(e) & 175 & 600 & 282 & 25 & 93 \\
\hline BPA-20PPGE(f) & 170 & 590 & 293 & 27 & 102 \\
\hline
\end{tabular}

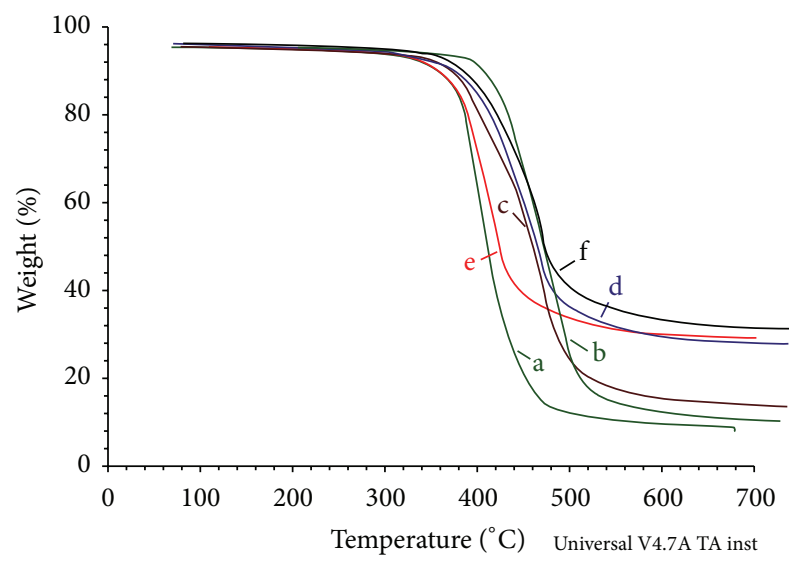

Figure 9: The TGA curves of epoxy-PPGE films in nitrogen at $10^{\circ}$ $(\mathrm{C} / \mathrm{min})$ heating rate.

4.3.3. Thermogravimetric Analysis. Thermogravimetric analysis gives a rapid evaluation of thermal stability of polymer matrix by determining the thermal degradation temperatures, char yields, and percentage of weight loss of epoxy matrix systems. The TGA curves of the unmodified and modified epoxy systems were shown in (Figure 9 and Table 5).

It is clearly seen from the TGA thermogram that incorporating imide and phosphorous moieties in the epoxy matrix has resulted in the enhancement of char percentage. It was observed that initial degradation temperature (IDT) of modified epoxy systems has reduced from $333^{\circ} \mathrm{C}$ to $282^{\circ} \mathrm{C}$; this is due to the presence of phosphorous groups which decomposes at relatively low temperatures on heating to form a phosphorous rich residue, which prevent the further decomposition of the resins by raising the decomposition temperature, and consequently results in higher char yield [16, 22-24]. Epoxy resins modified with imide compounds through chemical reactions or physical blending have been reported to show good flame retardant properties; it act as flame retardant by forming char in condensed phase [8], and hence PPGE modified epoxy yields better char as compared to the unmodified epoxy resin. The modified epoxy resin with high phosphorous content and high imide content is highly flame retardant with good thermal stability.

\section{Conclusion}

4-(N-Phthalimidophenyl) glycidylether (PPGE) and tripropyldiamine phosphine oxide (TADAP) were successfully synthesized and characterized. Bisphenol A type epoxy was modified using 4-(N-phthalimidophenyl) glycidylether, which contains both oxirane and imide groups.

Curing of the modified epoxy with TPDAP allows the incorporation of phosphorous into the polymer backbone. The ratio of PPGE was optimized for 15\%. Incorporation of PPGE in the epoxy network has resulted in the enhancement of mechanical, thermal, and flame retardant properties.

It was observed that flame retardancy of a system increases as a result of increasing amount of nitrogen and phosphorous content of the system. As we know that nitrogen and phosphorous are replacement for the halogens the combination of these two has resulted in the improvement of flame retardant and mechanical properties of the system.

This system can be potentially used as halogen free flame retardant coating system.

\section{Conflict of Interests}

The authors declare that there is no conflict of interests regarding the publication of this paper.

\section{References}

[1] S. Ghorabi, L. Rajabi, S. S. Madaeni, S. Zinadini, and A. A. Derakhshan, "Effects of three surfactant types of anionic, cationic and non-ionic on tensile properties and fracture surface morphology of epoxy/MWCNT nanocomposites," Iranian Polymer Journal, vol. 21, no. 2, pp. 121-130, 2012.

[2] C. Gerard, G. Fontaine, and S. Bourbigot, "New trends in reaction and resistance to fire of fire-retardant epoxies," Materials, vol. 3, no. 8, pp. 4476-4499, 2010.

[3] D. Derouet, F. Morvan, and J. C. Brosse, "Chemical modification of epoxy resins by dialkyl(or aryl) phosphates: Evaluation of fire behavior and thermal stability," Journal of Applied Polymer Science, vol. 62, no. 11, pp. 1855-1868, 1996.

[4] G. Camino, G. Martinasso, and L. Costa, "Thermal degradation of pentaerythritol diphosphate, model compound for fire retardant intumescent systems: part I-overall thermal degradation," Polymer Degradation and Stability, vol. 27, no. 3, pp. 285-296, 1990.

[5] Y. L. Liu, Y. C. Chiu, and C. S. Wu, "Preparation of silicon/phosphorous-containing epoxy resins from the fusion process 
to bring a synergistic effect on improving the resins' thermal stability and flame retardancy," Journal of Applied Polymer Science, vol. 87, no. 3, pp. 404-411, 2003.

[6] A. A. Kumar, M. Alagar, and R. M. V. G. K. Rao, "Synthesis and characterization of siliconized epoxy-1,3bis(maleimido)benzene intercrosslinked matrix materials," Polymer, vol. 43, pp. 693-702, 2002.

[7] C. Nguyen and J. Kim, "Synthesis of a novel nitrogenphosphorus flame retardant based on phosphoramidate and its application to PC, PBT, EVA, and ABS," Macromolecular Research, vol. 16, no. 7, pp. 620-625, 2008.

[8] T. Shiobara, S. Okuse, T. Aoki, and H. Kato, "Flame retardant epoxy resin compositions," US Patent 6,143,423, 2000.

[9] Y.-L. Liu, G.-H. Hsiue, Y.-S. Chiu, R.-J. Jeng, and C. Ma, “Synthesis and flame-retardant properties of phosphoruscontaining polymers based on poly(4-hydroxystyrene)," Journal of Applied Polymer Science, vol. 59, no. 10, pp. 1619-1625, 1996.

[10] S. Banerjee, S. K. Palit, and S. Maiti, "Phosphorus containing polymers. III. polyimidophosphonates," Journal of Polymer Science Part A: Polymer Chemistry, vol. 32, no. 2, pp. 219-227, 1994.

[11] M. Banks, J. R. Ebdon, and M. Johnson, "The flame-retardant effect of diethyl vinyl phosphonate in copolymers with styrene, methyl methacrylate, acrylonitrile and acrylamide," Polymer, vol. 35, no. 16, pp. 3470-3473, 1994.

[12] Y.-L. Liu and Y.-J. Chen, "Novel thermosetting resins based on 4-(N-maleimidophenyl)glycidylether: II. Bismaleimides and polybismaleimides," Polymer, vol. 45, no. 6, pp. 1797-1804, 2004.

[13] A. Toldy, P. Anna, I. Csontos, A. Szabó, and G. Marosi, "Intrinsically flame retardant epoxy resin-fire performance and background-part I," Polymer Degradation and Stability, vol. 92, no. 12, pp. 2223-2230, 2007.

[14] S. Ahmad, F. Naqvi, E. Sharmin, and K. L. Verma, "Development of amine-acid cured Annona squamosa oil epoxy anticorrosive polymeric coatings," Progress in Organic Coatings, vol. 55, no. 3, pp. 268-275, 2006.

[15] E. Sharmin, M. S. Alamb, K. Renjish, B. Philip, and S. Ahmad, "Linseed amide diol/DGEBA epoxy blends for coating applications: preparation, characterization, ageing studies and coating properties," Progress in Organic Coatings, vol. 67, pp. 170-179, 2010.

[16] T. S. Wang, J. K. Parng, and M. D. Shau, "The synthesis and properties of new epoxy resin containing phosphorus and nitrogen groups for flame retardancy," Journal of Applied Polymer Science, vol. 74, no. 2, pp. 413-421, 1999.

[17] L. Gao, D. Wang, Y. Wang, J. Wang, and B. Yang, "A flameretardant epoxy resin based on a reactive phosphoruscontaining monomer of DODPP and its thermal and flameretardant properties," Polymer Degradation and Stability, vol. 93, no. 7, pp. 1308-1315, 2008.

[18] D. W. van Krevelen, "Some basic aspects of flame resistance of polymeric materials," Polymer, vol. 16, no. 8, pp. 615-620, 1975.

[19] V. Krevelen and P. J. Hoftyzer, Their Estimation Correlation with Chemical Structure, Properties of Polymer, Elsevier, New York, NY, USA, 2nd edition, 1976.

[20] X. Chen, Y. Hu, C. Jiao, and L. Song, "Preparation and thermal properties of a novel flame-retardant coating," Polymer Degradation and Stability, vol. 92, no. 6, pp. 1141-1150, 2007.

[21] Z. G. Huang and W. F. Shi, "Thermal behavior and degradation mechanism of poly(bisphenyl acryloxyethyl phosphate) as a UV curable flame-retardant oligomer," Polymer Degradation and Stability, vol. 91, no. 8, pp. 1674-1684, 2006.

[22] K. S. Annakrtty and K. Kishore, "Flame retardant polyphosphate esters: 1. Condensation polymers of bisphenols with aryl phosphorodichloridates: synthesis, characterization and thermal studies," Polymer, vol. 29, no. 4, pp. 756-761, 1988.

[23] P. Kannan and K. Kishore, "Novel flame retardant polyphosphoramide esters," Polymer, vol. 33, no. 2, pp. 418-422, 1992.

[24] M. Banks, J. R. Ebdon, and M. Johnson, "Influence of covalently bound phosphorus-containing groups on the flammability of poly(vinyl alcohol), poly(ethylene-co-vinyl alcohol) and lowdensity polyethylene," Polymer, vol. 34, no. 21, pp. 4547-4556, 1993. 

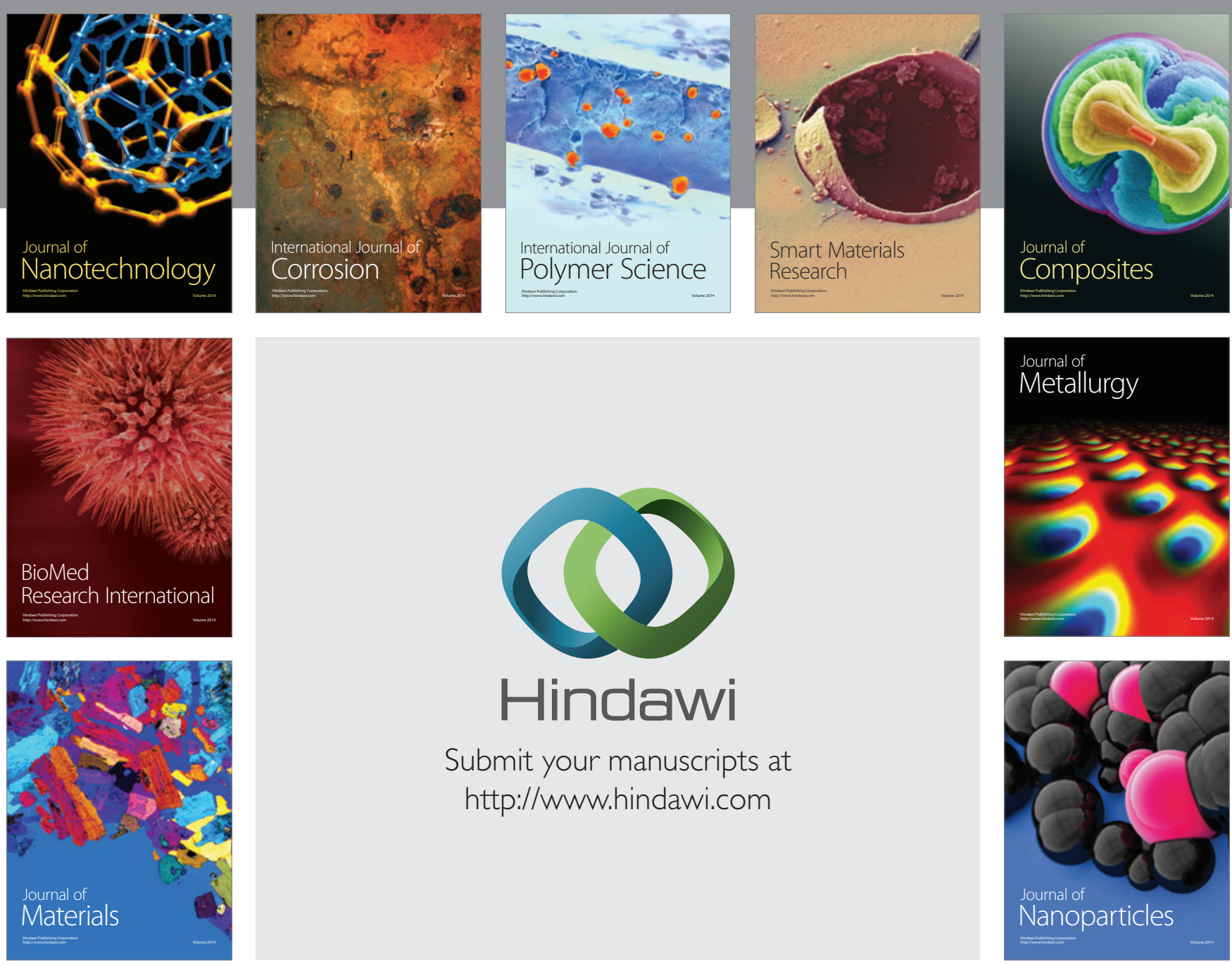

Submit your manuscripts at http://www.hindawi.com
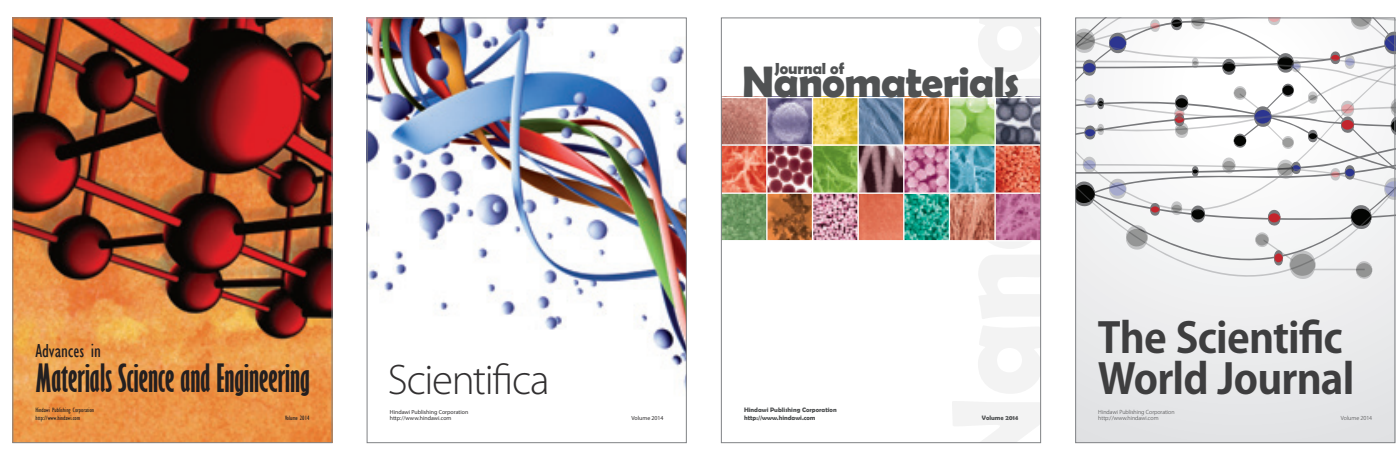

\section{The Scientific World Journal}
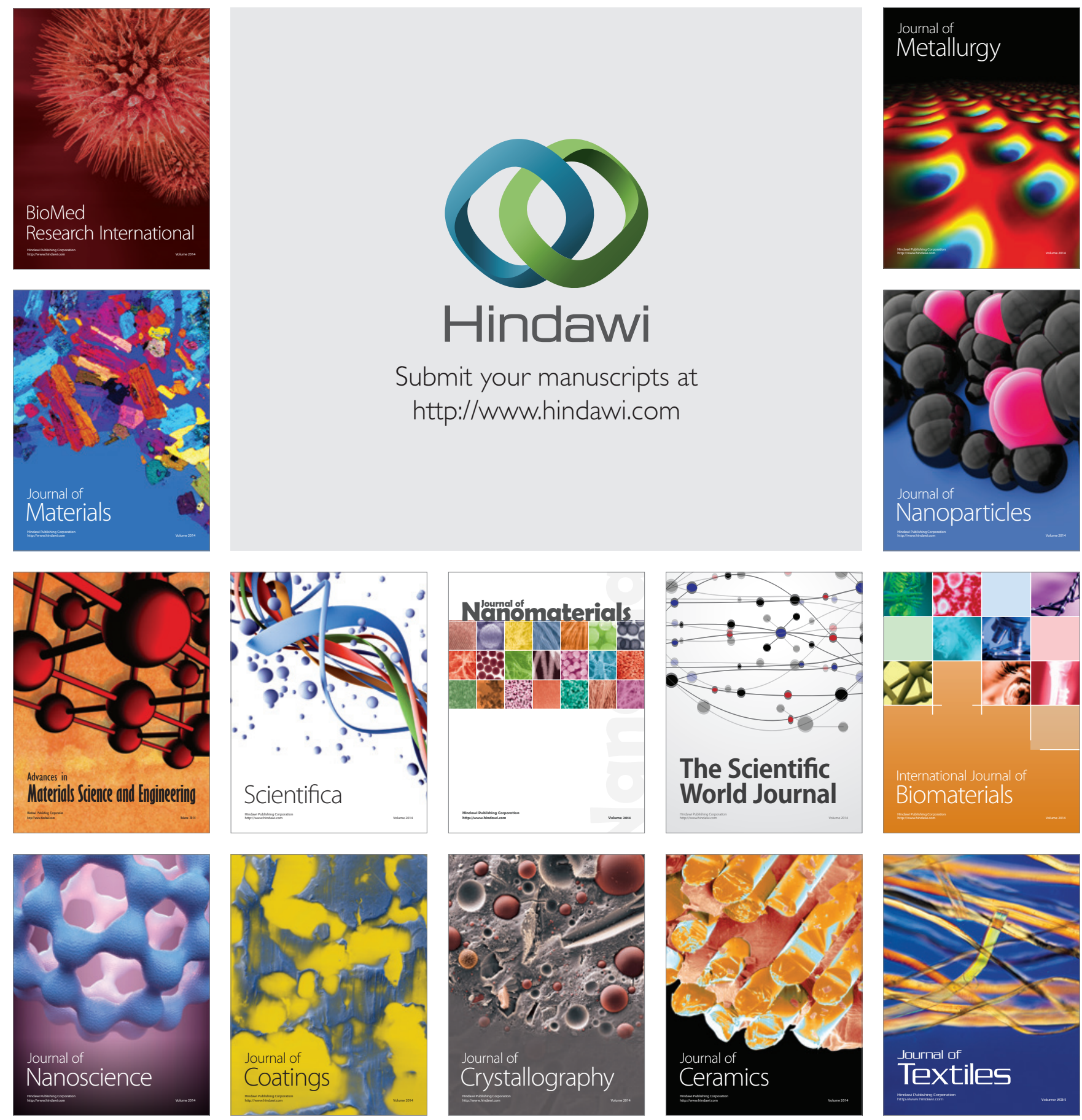